\title{
Studies on epizootic microsporidiosis in wild dusky grouper (Epinephelus guaza) from Mediterranean sea at Matrouh Governorate, Egypt
}

\author{
Mohamed S. Marzouk ${ }^{1}$; Olfat M. Anter ${ }^{1}$; Mohamed M. Ali ${ }^{1}$; \\ Amany M. Kenawy ${ }^{2}$ and Mahmoud A.Mahmaud ${ }^{1}$ \\ 1- Faculty of Veterinary Medicine, Cairo University \\ 2- National Reasearch Center, Dokki, Gizza, Egypt
}

\begin{abstract}
$\mathrm{T}$ his study was carried out on 476 wild marine Dusky Grouper (Epinephelus guaza), captured from the West North shore of Mediterranean Sea at Matrouh Governorate from Sept. 2005 to Sept. 2006. The total prevalence of microsporidia among wild Epinephelus guaza fish was found to be 301 (63.23 $\%$ ). The investigated fish, revealed the presence of cyst-like nodules ( xenomas, 2-4 mm. in diameter) in the gill arches. Each gill arch was infected with (1-5) xenomas and up to 30 nodules per fish. The recovered spores of Glugea anomala appeared as thick walled, uni-nucleated, pear-oval in shape with large vacuole. They measured (3-4 $\mu \mathrm{m})$ in width and $(5-6 \mu \mathrm{m})$ in length. The highest prevalence $(82.9 \%)$ was recorded in summer, while the lowest one $(30.33 \%)$ was recorded in winter. Presently, the highest infection rate $(88.8 \%)$ with Glugea anomala was recorded among fish with 200-250g body weight, while the lowest one (43.3\%) was recorded among fish of 100-150g body weight. The main histopathological alteration in gills was destruction of gill filaments with degenerative changes and infiltration of mononuclear leukocytes. The water parameters revealed the highest $\mathrm{pH}(7.3)$, chloride value $(240 \mathrm{mg} / \mathrm{L})$ and the total hardness $(290 \mathrm{mg} / \mathrm{L})$ in summer, while the lowest $\mathrm{pH}(5.7)$ and the total hardness $(217 \mathrm{mg} / \mathrm{L})$ were recorded in winter, but the lowest chloride value $(122$ $\mathrm{mg} / \mathrm{L}$ ) was recorded in autumn.
\end{abstract}

Keywords: Dusky grouper,Epinephelus guaza, epizootic microsporidiosis, Mediterranean sea, Matrouh, Egypt

\section{INTRODUCTION}

The drastic shortage of animal food from animals and with the world's increasing need of fish either from natural water resources or from fish cultures spotlighted the importance of fishes, but the parasitic infections are one of the main problems facing fish production (Scott, 2006)

Microsporidiosis is a serious parasitic and potentially lethal disease in wild, cultured, marine, and freshwater fishes. It is considered of the most economically important diseases of marine fishes (Harres, 2005; Buron, 2006). 
Microsporidia is widely distributed intracellular in protozoan parasites in fishes characterized by the presence of gross nodules (xenomas) in different organs of infected fishes as well as the edible muscular parts that reduced the productivity and marketability of infected fishes (Dykova, 1995; Molnar, 2005).

In coastal countries like Egypt, the commercial fishing catch from natural water resources constitutes the main source of fish production. Commercial marine fishes at the coastal regions of the Mediterranean Sea, particularly in the North West area at Matrouh Governorate are considered very important in viewing the prevalence of different parasitic diseases marine fish.

From the fore mentioned overview, this study was planned to survey, and identify of the protozoan parasites of the wild marine fish (Dusky Grouper; Epinephelus guaza). It also aimed to study effect of different environmental factors on the detected protozoan, clinical signs and histopathological lesions in infected fish at Matrouh Governorate, Egypt.

\section{MATERIALS AND METHODS}

Atotal number of 476 wild Dusky Grouper (Epinephelus guaza) were randomly collected alive or freshly dead from marine water at the North West shore of Mediterranean sea at Matrouh Governorate, Egypt. The fish were collected throughout one year from September, 2005 to September, 2006 and their body weight ranged from 100 to $250 \mathrm{~g}$ and the total body length ranged from 17-29 $\mathrm{cm}$. Fish samples were promptly transported to laboratory of the provential Animal Health Research Institute of Matrouh for clinical and parasitological investigation.

All collected fish were clinically examined for detection of any external or internal visible parasites on or in their bodies (skin, fins, gills, branchial cavity, eye, mouth, liver, kidneys, and muscles) according to Conroy and Hermann (1981).

The collected parasitic nodules were washed in saline solution then prepared on permanent slides (Hoffman, 1970). The nodules were ruptured and wet mount smears were prepared from the milky material oozing out from the nodules and left to be dried. The dried mounts were fixed in absolute methyl alcohol and left for dehydration, then stained by Giemsa stain according to John et al. (1990).

The identification of the recovered sporozoan parasites was based on morphological characters according to Lom (1994) and Paperna (1996).

For physico-chemical water analysis, water samples were collected parallel to the fish sampling in clean glass bottles of $500 \mathrm{ml}$ capacity to be subjected for examination of temperature, $\mathrm{pH}$, ammonia, nitrite, nitrate, chloride and total hardness.

For histopathological examination, the heavily infected fish gills were excised and preserved in $10 \%$ buffered neutral formalin. The tissue specimens of naturally infected fish were dehydrated; parafinized then sectioned at $3-5 \mu \mathrm{m}$ 
thickness, and stained with Haematoxyline and Eosin (H.\&E.) according to Carleton et al. (1976), Gram stain according to Collins et al.(1975) and Periodic Acid Schiff (P.A.S.) stain according to Lucky (1977), Kabata (1985) and Crookham et al. (1991).

\section{RESULTS}

Examination of the 476 wild marine Dusky Grouper (Epinephelus guaza) captured from the west north shore of Mediterranean sea at Matrouh, Governorate from September (2005-2006) revealed no external clinical signs or abnormalities (Photo1). The total prevalence of microsporidia among wild Epinephelus guaza fish was 301 fish with a percentage of $63.23 \%$.

The parasitological examination of investigated marine fish, revealed in diameter cyst-like nodules or xenomas of 2-4 mm; round or oval shaped with white, pale yellow to yellowish colour. They were attached or embedded on the gills (Photo 2). Each gill arch was infected with (1-5) xenomas (Photo 3), while up to 30 nodules were detected per fish. No postmortem lesions were seen in the internal organs. The highest intensity of nodules (xenomas) was 5/gill arch among 17 infected fish with prevalence of 5.64\%, while the lowest intensity was one xenoma in 95 fish with a prevalence of $31.56 \%$.

The identification of the recovered sporozoan parasite was based on morphometrical characteristics and so it appeared to be belonging to order: Microsporidia, Family: Gluguidea, genus: Glugea and species: anomala according to Lom (1994) and Paperna (1996).

The recovered spores of Glugea anomala appeared as thick walled, uninucleated, pear-oval shaped with a large vacuole. They measured (3-4 $\mu \mathrm{m})$ in width and $(5-6 \mu \mathrm{m})$ in length. The Giemsa stained spores from infected gills had small bodies with blue to dark blue colour (Photo 4).

The seasonal prevalence of Glugea anomala in Epinephelus guaza revealed a high infection rate in summer $(82.9 \%)$, followed by spring $(58.7 \%)$, then autumn and winter $(71.4 \%$ and $30.33 \%)$, respectively (Table 1$)$.

Table (1): Seasonal prevalence of Glugea anomala collected from naturally infected Dusky Grouper (Epinephelus guaza )

\begin{tabular}{|c|c|c|c|}
\hline Season & No. of examined fishes & No. of infected fishes & Prevalence \% \\
\hline Spring & 160 & 94 & 58.7 \\
\hline Summer & 141 & 117 & 82.9 \\
\hline Autumn & 84 & 60 & 71.4 \\
\hline Winter & 91 & 30 & 30.33 \\
\hline Total / year & 476 & 301 & 63.23 \\
\hline
\end{tabular}

Concerning, the prevalence of Glugea anomala in Epinephelus guaza the highest infection rate $(88.8 \%)$ was detected among fish of $200-250 \mathrm{~g}$. body weight, while the lowest rate $(43.3 \%)$ was detected among fish of $100-150 \mathrm{~g}$. 
body weight (Table 2). The estimated physico-chemical water parameters revealed the highest $\mathrm{pH}$ (7.3) in summer and the lowest one (5.7) in winter. The total ammonia, nitrate, nitrite and phosphate were negative. Moreover, the highest value of chloride $(240 \mathrm{mg} / \mathrm{L})$ was detected in summer, while the lowest one $(122 \mathrm{mg} / \mathrm{L})$ was recorded in autumn. The total hardness was higher in summer $(290 \mathrm{mg} / \mathrm{L})$ and lower in winter $(217 \mathrm{mg} / \mathrm{L})($ Table 3$)$.

Table (2): Prevalence of Glugea anomala collected from naturally infected Dusky Grouper (Epinephelus guaza) in relation to their body weights

\begin{tabular}{|c|c|c|c|}
\hline Fish Body weight & No. of examined fishes & No. of infected fishes & Prevalence \% \\
\hline $100-150 \mathrm{~g}$. & 120 & 52 & 43.3 \\
\hline $150-200 \mathrm{~g}$. & 176 & 89 & 50.5 \\
\hline $200-250 \mathrm{~g}$. & 180 & 160 & 88.8 \\
\hline
\end{tabular}

Table (3): Physico-chemical water parameters in different seasons

\begin{tabular}{|c|c|c|c|c|}
\hline $\begin{array}{c}\text { Water } \\
\text { parameter }\end{array}$ & Summer & Winter & Autumn & Spring \\
\hline Temperature & $23-27 \circ \mathrm{C}$ & $5-10 \circ \mathrm{C}$ & $11-15 \circ \mathrm{C}$ & $15-23 \dot{\mathrm{C}}$ \\
\hline $\mathrm{pH}$ & $6.6-7.3$ & $5.7-6.0$ & $6.0-6.5$ & $6.2-6.9$ \\
\hline $\begin{array}{c}\text { Ammonia } \\
(\mathrm{mg} / \mathrm{L})\end{array}$ & Negative & Negative & Negative & Negative \\
\hline $\begin{array}{c}\text { Nitrate } \\
(\mathrm{mg} / \mathrm{L})\end{array}$ & Negative & Negative & Negative & Negative \\
\hline $\begin{array}{c}\text { Nitrite } \\
(\mathrm{mg} / \mathrm{L})\end{array}$ & Negative & Negative & Negative & Negative \\
\hline $\begin{array}{c}\text { Phosphate } \\
(\mathrm{mg} / \mathrm{L})\end{array}$ & Negative & Negative & Negative & Negative \\
\hline $\begin{array}{c}\text { Chloride } \\
(\mathrm{mg} / \mathrm{L})\end{array}$ & $220-240$ & $130-200$ & $122-150$ & $133-200$ \\
\hline $\begin{array}{c}\text { Hardness } \\
(\mathrm{mg} / \mathrm{L})\end{array}$ & $270-290$ & $217-252$ & $234-241$ & $242-265$ \\
\hline
\end{tabular}

The histopathological alterations in the infected fish gills included distortion of the secondary lamellae which was distributed focally along their length, associated with degenerative changes in the form of hydropic degeneration mainly in respiratory epithelial cells. Meanwhile, sites devoid of these cells types due to their necrosis and desquamation could be observed in some areas. Moreover, calcifications was demonstrated in the areas of necrosis (Photo 5). The lamellar blood vessels were dilated and engorged with blood cells.

More advanced changes were manifested by epithelial hyperplasia and lamellar fusion of the secondary lamellae leading to obliteration of the inter lamellar space (Photo 6). Mononuclear leucocytes (macrophages and lymphocytes) were infiltrated inbetween the lamellar epithelial cells (Photo 7). 
The microscopic examination of infected fish gills showed xenomas with large number of spores (Photos $8 \& 9$ ) inbetween the secondary lamellae at the inter lamellar space (Photo 10).

The spores appeared as small sized $(4-6 \mu \mathrm{m})$ oval to pear shaped, mono nucleated bodies. They appeared as dark blue bodies with H \& E stain (Photo 11 ) and as red dots with PAS stain (photo 12). Gram stained specimens showed small bodies with blue to dark blue colour (Photo 13). In H \& E stained sections, most of xenomas induced focal epithelial desquamation and or hyperplasia in the secondary lamellae and mononuclear leuocytic infiltration. Moreover, proliferation fibroblast and fibrous connective tissue formation surrounded the xenomas (Photo 14).

\section{DISCUSSION}

Microsporidiosis is a serious parasitic and potentially lethal disease in wild, cultured, marine, and freshwater fishes. It is considered of the most economically important diseases of marine fishes (Harres, 2005).

In the present study, the naturally infected wild marine Dusky Grouper (Epinephelus guaza) revealed no pathognomonic clinical signs or external abnormalities to micrsporidiosis. The only lesions were restricted to the infected fish gills as numerous macroscopic, cyst-like, yellow to orange nodules. This result agreeds with the findings of Eissa (2002), that no characteristic signs were associated with microsporidiosis in infected fishes. This may be attributed to nature of the disease and species of the infected fish and the parasite in which a localized disease was only demonstrated.

The numerous cyst like nodules (xenomas) which were found in gills of naturally infected fish are different in shape, color and size. The nature and description criteria of these xenomas are more or less similar to the findings given by Eissa (2002) and Kalantan (2004).

The intensity of the nodules varying from 1 up to 5 / gill arch and 30 per infected fish. Different values of microsporideal nodular lesions were reported by many authors as Eissa (2002) who counted 3-56 nodules / Hake fish, while Sanchez (2006) detected only one xenoma of Microsporidia (Glugea sp.) / fish. The difference in the intensity of infection / fish could be attributed to several factors of which the fish species, age, size, sex and feeding habits are important. Also, the environment and its suitability for the invasive parasite could play an effective role in the infection process. This explanation is supported by the findings of many authors (Ramsay et al., 2001 and Eissa, 2002).

The prevalence of the investigated wild Grouper fish with Glugea anomala collected from West North shore at Matrouh Governorate, Egypt reached $63.23 \%$. Different prevalence rates were recorded for microsporidiosis by Eissa (1995), who gave $40-60 \%$ in naturally infected Hake fish collected from Red Sea at Suez Governorate, Egypt, while Gandhi et al. (1995) recorded 
only $12 \%$. These variations could be explained by the different environment and the site of sample collection in rainbow trout fish.

Moreover, the present prevalence of Glugea anomala infection among wild marine Grouper fish was recorded to be highest in summer $(82.9 \%)$ followed by autumn (71.4\%) then spring (58.7\%) and finally winter (30.33\%).Such value in autumn is comparatively higher than in spring which may be attributed to the lower number of examined fishes (84) compared with (160) examined in Spring. Different seasonal prevalence rates were recorded by many authors (Eissa, 1995; Ebrahim \& Khattab, 2000 and Abd El-Aal, 2002).

Concerning the relationship between the infected fish weight and the prevalence of Glugea anomala, the present results indicated a positive correlation in which the prevalence increased in larger fish where the values were $88.8 \%, 50.5 \%$ and $43.3 \%$ in fish with $200-250 \mathrm{~g} ., 150-200 \mathrm{~g}$. and $100-$ $150 \mathrm{gm}$. respectively. These results supported those of Ebrahim and Khattab (2000) and Eissa, (2002).

The water physical and chemical parameters are usually the way to understand the epizootiology of fish diseases. In this study, the results indicated that. The highest water temperature was recorded in summer $\left(23-27^{\circ} \mathrm{C}\right)$; while it reached as low as $\left(5-10^{\circ} \mathrm{C}\right)$ in winter. Many authors reported that the microsporidian infection is temperature dependant and it increases with temperature (Abd El-Aal, 2002). The explanation for the high infection rate with Glugea anomala in the examined Grouper fish at high water temperature could be attributed to the excess infected zoo plankton eaten by the susceptible fish. Also, Hank (2006) recorded that higher water temperature is essential for high infection, while at lower temperature $\left(4^{\circ} \mathrm{C}\right)$, the microsporidian spores become dominant but they can keep their viability for up to 1 year at this low temperature.

Concerning the $\mathrm{pH}$ values of water samples collected with fish samples, they were almost in vary narrow range (6-7). This could be attributed to the wide area of fishing and absence of chemical pollution in this area. Kyung and Claude (2005) reported that the decrease of $\mathrm{pH}(5-8)$ can act as a barrier against skin and gill parasitic infection. This could also explain the high prevalence of Glugea anomala infection in Grouper fish in summer (pH 6.6-7.3) and the lower prevalence in winter (pH 5.9-6.8).

Regarding the other chemical water parameters namely ammonia, nitrate and nitrite the results proved that all these chemicals were not detected, indicating that the water in this area is quite away from organic and chemical pollution. Also, the values of the main salts namely chlorides and carbonates were within the normal levels, indicating the suitability of future Mariculture in floating lags in this area. This is also supported by the absence of phosphate which with nitrogen can lead to water eutrophiceus with the result of excessive algal blooms which usually have an adverse impact on fishes. 
Concerning the Histopathological examination of the tissues of naturally infected Grouper fish, it was clear that the tissue alterations were localized to the fish gills. The macroscopic examination revealed the presence of white to yellowish nodules (xenomas), with 2-4 mm diameter embedded in gill filaments or gill lamellae. The number of xenomas was 1-5/gill arch and 30/ fish. Using differential stains, the microspora (Glugea anomala) were stained specifically with Gram stain and appeared in sections as blue bodies, while using the PAS, they take red coloration. Xenomas with large numbers of spores were embedded inbetween the secondary lamellae in the interlamellar space, where the spores appeared mononucleated oval to pear-shaped of small size with diameters from 4-6 $\mu \mathrm{m}$. Moreover, the xenomas are surrounded by hyperplastic tissue with mononuclear leucuocytic infiltration in the secondary lamellae. Also, focal epithelial desquamation was noticed; however, rapid proliferation of fibroblasts and fibrous connective tissue was noticed surrounding the xenomas. These results supported those reported by Gandhi et al. (1995) in rainbow trout taken from a fish farm in South-West England. Also, Ebrahim and Khattab (2000) and Eissa (2002) in fishes infected with microsporidian parasites.

The associated microscopical tissue alterations varied according to the degree of infection was manifested by slight destruction of gill lamellae, degenerative changes (hydropic degeneration in respiratory epithelial cells) necrosis, desquamation with calcification in necrosed area and congestion in blood vessels. Hyperplasia in epithelial cells of lamellae, lamellar fusion, infiltration of mononuclear leucocytes macrophages and lymphocytes, rapid proliferation of fibroblast and fibrous connective tissue associated with lamellar fusion were also common. These findings supported those reported by Gandhi et al., (1995) in rainbow trout infested with microsporidia, (Dykova, 1995) in freshwater and marine fishes and (Eissa, 2002) in Hake fish.

Concerning the microscopical examination of the parasitic smears taken from the lesions of naturally infested Grouper fish and stained with different stains, they revealed oval spores that appeared as dark blue dots, when stained by Giemsa stain, dark blue when stained by Gram stain, $(\mathrm{G}+\mathrm{ve})$. Using $\mathrm{H}$ and $\mathrm{E}$ stain, they appeared as oval blue dots. By Periodic Acid Schiff (PAS) stain the spores revealed a positive reaction as they appeared red dots. The identification procedure indicated the microsporidean protozoa as Glugea anomala. Similar findings were reported by Ebrahim and Khattab( 2000) who recorded that the spores revealed positive reaction when stained by Gram and PAS stains while theystained dark blue with Giemsa. Eissa (2002) found oval spores with cresentic polar capsules appearing as dense area and when stained revealed Gram and PAS (+ ve). Also Gram stain was used to exclude other protozoal spores sinces microsporidians are the only protozoal spores that are Gram positive. 


\section{Conclusion}

This study proved the suitability of the area at the northern west coast of the Egyptian Mediterranean Sea for the future Mari-culture. The only adverse impact is the wide spread of some parasites in particular the microsporidian protozoa such as Glugea anomala infecting one of the most popular and expensive reef fish, namely the Dusky Grouper (Epinephelus gauza) at a high prevalence especially in summer. Also, the results indicated the localized form of infestation with microsporidian parasite to the gills of the infested fish. Further investigations concerning the control measures for prevention of such parasites should be carried out.

\section{REFERENCES}

Abd EI-AaI, M. (2002). Studies on some tissue parasites in fish. PH. D. Vit. Sc. Thesis, Tanta University.

Buron, I. (2006). Text book of fish disease T.F.H. publ, west Sylvania. 10(3): 187-190.

Carleton, H.; Drury, A.; Willington, E. and Coneron, H. (1976). Carleton histological techniques $4^{\text {th }}$ Ed., Oxford Unv. Press, 4A., Toronto.

Collins, C.; Parricia, M. and Grange, J. (1975). Microbiological methods. Idintification methods. Seven edition, 103.

Conoary, A. and Hermann, R. (1981). Postmortem examination of fish. T. F. H. Pubi, 2:150-155.

Crookham, J. and Dapson, R. (1991). Hazardous chemicals in the histopathology laboratory, $2^{\text {nd }} \mathrm{Ed}, 1991$, Anatec.

Dykova, I. (1995). Phylum Microspora. Fish diseases and disorders (Woo, P. T. K.) volume 1. protozoan and metazoan infection, pp.149-179.

Ebrahim, M. and Khattab, M. (2000). Histopathological and parasitological investigation on microsporidian (Pleistophora sp.) infection in muscular tissue of marine fish at the eastern province of Saudi Arabia. Journal of the Egyptian Veterinary Medical Association. 60 (1):79-87.

Eissa, M. (1995). Studies on parasitic diseases in marine Hake fish (Saurus tumbil) for the first time in Egypt. Zagazig Vet. Univ., 23(4): 90-93.

Eissa, M. (2002). Diseases Caused by Microsporidia. Parasitic fish diseases in Egypt. Dar El-Nahda El-Arabia Publishing, First Edition, pp.54-58. 
Gandhi, S.; Locatelli, L. and Feist, W. (1995). Occurrence of Loma sp. (Microsporidia) in farmed rainbow trout Oncorhnchus mykiss at a site in south west England. Bulletin of the European Association of Fish Pathologists. 15(2): 58-60.

Hank, H. (2006). Studies of temp. effect on parasites . Journal of Fish Disease, 12(3): 17-25.

Harres, P.D. (2005). Econmical importance of Microsporidia. Vet. Med. J. 5 (3):33-35.

Hoffman, L. (1970). Parasites of North American freshwater fishes, Berkeley, University of California Press.

John, D.; Alan, S. and David, R. (1990). Theory and practice and histological techniques, third edition, $307 \mathrm{pp}$.

Kabata, Z. (1985). On two little-known micosporidia of marine fishes. Parasitol., 49: 309-315.

Kalantan, A.M.W. (2004). Protozoan parasites of fishes, 10(5): 371-378.

Kyung, H.Y. and Claude, E.B. (2005). Hydrology and water supply for pond aquaculture. Auburn Univ., Alabama, 442 pp.

Lom, J. (1994). Protozoan parasites of fishes identification and Taxonomy of microsporidia, $2^{\text {nd }}$ Ed., 4:150-157.

Lucky, Z. (1977). Using of PAS stain. J. fish Dis., 13(5): 3-5.

Molnar, K. (2005).Morphology of Microsporidia. Vet. Parasites., 6 (6):245-277.

Paperna, I. (1996).Vetrinary parasites identification and Taxonomy of microsporidia, 3(5):130 -139.

Ramsay, J.M.; Speare, J.; Sanchez, G. and Daley, J. (2001). The transmission potential of Loma salmonae (Microspora) in the rainbow trout, Oncorhynchus mykiss (Waalbaum), is dependent upon the method and timing of exposure. Journal of Fish Diseases, 24(8):453-460.

Sanchez, G. (2006). Study of microsporidian spores. European association of fish pathologists, 15(6): 200-201.

Scott, A. p. (2006). Studies on Fish Culture. $2^{\text {nd }}$ Ed., 10: 250-255. 


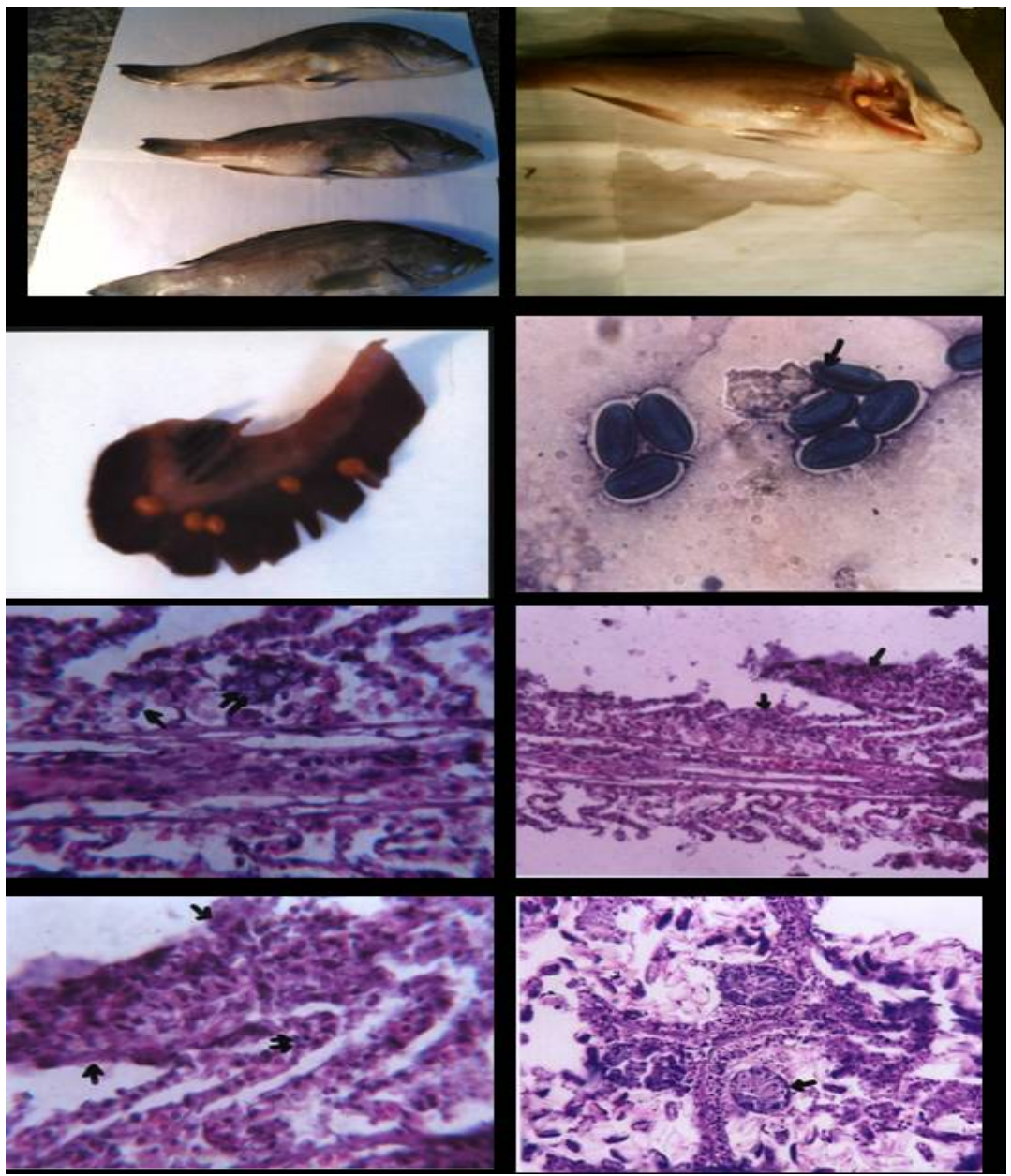

Photo (1) Naturally catched Dusky Grouper (Epinephelus guaza).

Photo (2) Large size (2mm)xenomas appear in gills of naturally infected Dusky Grouper (Epinephelus guaza).

Photo (3) Tumer-like nodules in gill arch of naturally infected Dusky Grouper (Epinephelus guaza).

Photo (4) Spores of Microsporidia (glugea anomala) stained with Giemsa stain (X1000).

Photo (5) Infected gill showed, degenerative changes, necrosis, and desquamation of respiratory epithelial cells (arrow) and focal calcification inbetween secondary lamellae (2 arrows). (H \& E, X1000)

Photo (6) Infected gills showing epithelial hyperplasia, (arrow). (H \& E, X200).

Photo (7) Infected gills showing epithelial hyperplasia (arrow) and mononuclear leucocytic infiltration inbetween the secondary lamellae (2 arrow) (H \& E, X1000).

Photo (8) Cross section in xenomas showing large numbers of microsporidia spores. (H \& E, $\mathrm{X} 400)$. 


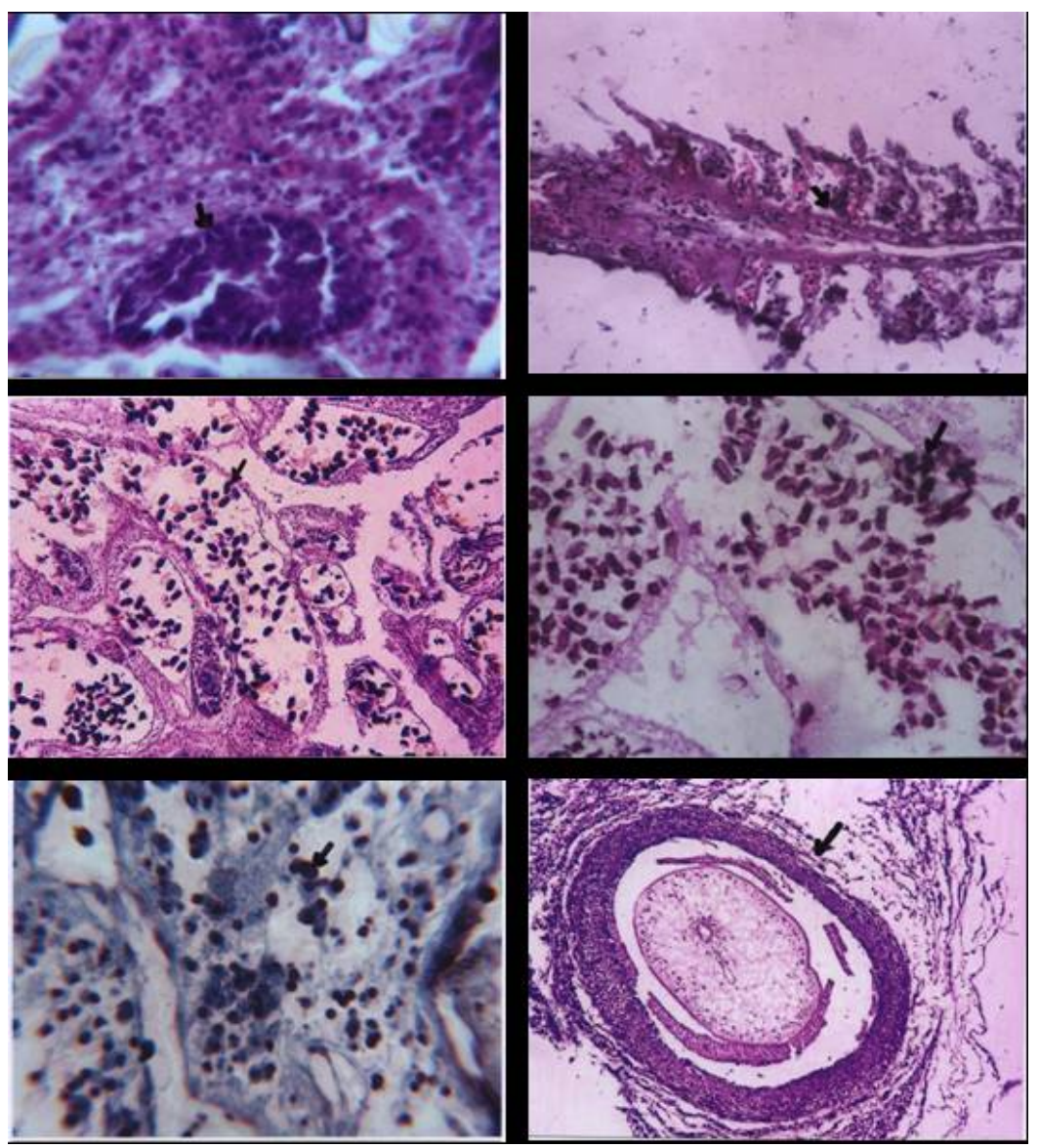

Photo (9) Cross section in xenomas showing large numbers of spores (arrow).(H \& E, X1000). Photo (10) Infected gills showing xenomas in between the secondary lamellae (arrow). (H \& E, X200).

Photo (11) Infected gills showing dark blue Glugea anomala spores. (H \& E, X1000)

Photo (12) Infected gills showing red Glugea anomala (PAS stain, X1000).

Photo (13) Infected gills showing blue to dark blue Glugea anomala (Gram's stain, X400).

Photo (14) Cross section in xenomas surrounded with granulomataus reaction (macrophages, lymphocytes and fibrous C. T). (H \& E, X400). 